\title{
COGNITIVE DISTORTIONS OF PATIENTS IN THE GAMBLING ADDICTS' CLUB - DIFFERENCES WITH REGARD TO AGE AND LENGTH OF TREATMENT
}

\author{
Donald Stojnić $^{1}$, Neven Ricijaš ${ }^{2}$ \& Zoran Zoričić ${ }^{1}$ \\ ${ }^{1}$ Department of Psychiatry, Clinical Hospital Centre "Sestre Milosrdnice", Zagreb, Croatia \\ ${ }^{2}$ University of Zagreb, Faculty of Education and Rehabilitation Sciences, Zagreb, Croatia
}

received: 16.2.2018;

revised: 18.10.2018;

accepted: 30.11 .2018

\section{SUMMARY}

Background: Cognitive processes are important factors in the aetiology of pathological gambling and they are always important aspect of all gambling interventions. Among other things, the gamblers' decision-making process and persistence in gambling is under the influence of their perception of the importance of knowledge/skills versus luck in different gambling activities. In this study, we examine cognitive distortions of pathological gamblers and their perceptions on the significance of luck versus knowledge/skills in different games of chance. Effects of age and length of treatment are also examined.

Subjects and methods: A total of 65 pathological gamblers at the gambling addicts' club in Zagreb were included in the study. Cognitive distortions were measured using a modified version of the Gambling related cognitive distortions scale (Ricijaš et al. 2011). Participant thoughts on the role of luck versus knowledge/skills in games of chance were measured with a questionnaire especially designed for this study. All instruments were self-assessment questionnaires and anonymously filled out during a group sessions.

Results: In general, results showed moderate cognitive distortions in terms of gambling beliefs, but significant perception of the importance of knowledge/skills for some games, especially sports betting and card games. Younger patients and patients in treatment for longer period have lower illusion of control. Length of treatment also seem to effect gambling-related superstition beliefs and incorrect understanding of probability, as well as importance of knowledge/skills for success in sports betting and card games.

Conclusions: The results of this study lead to the indirect conclusion that length of treatment is a positive factor, which likely influences gamblers' cognitive distortions. This conclusion certainly requires additional examination using longitudinal studies, which would provide a better overview of whether these differences are in fact due to the length of treatment and also to confirm its value for future abstinence from gambling activities.

Key words: pathological gambling - games of chance - cognitive distortions - treatment

\section{INTRODUCTION}

Since the mid 1980s, great attention has been focused on the role of cognitive processes in the aetiology and maintenance of problematic and pathological gambling behaviour. The central assumption of this approach is that decision-making in gambling is not entirely objective and rational. This process is under the strong influence of numerous erroneous or irrational perceptions, and biases that lead to changes in expectations on the likelihood of wins and losses (Sharpe \& Tarrier 1993). Just as an optical illusion will make people think they are seeing something other than what they are really seeing, there are also illusions of causality that lead people to believe that one event causes another, while objectively there are no links between them. The illusion of causality is one way that the human mind has evolved to extract causality from chance (Matute et al. 2015) and when one seeks to find sense and patterns in random situations, cognitive distortions will probably be developed. Pathological gamblers try to control and predict events that, objectively, occur by chance and are by nature uncontrollable. Therefore, they develop illusion of control and superstition believes that motivate them to create tactics and skills in order to increase the likelihood of victory (Toneatto et al. 1997, Xian et al. 2008).

Cognitive distortions (biases) or irrational beliefs represent the fundamental element of gambling pathology (Fortune \& Goodie 2012). Ladouceur (2004a) divided them into three main categories: (1) incorrect understanding of probability, (2) illusion of control, and (3) superstitions. But no matter which cognitive distortion dominates in a gambler's mind, the goal is always the same - inclination to have control over random, uncontrollable gambling events.

As gambling related irrational beliefs and behaviours support persistence in gambling activities and contribute to the development of problematic/pathological gambling, international studies have been quite consistent in their findings that social and problem gamblers differ in gambling related cognitive distortions (Ladouceur 2004b, Xian et al. 2008, Myrseth et al. 2010).

Even though cognitive mechanisms play an important part in the emergence and maintenance of a gambling problem (Levesque et al. 2018), together 
with emotional/psychological vulnerability, cognitive distortions per se are challenging to measure. The main methodological challenge in defining and measuring cognitive distortions relates to the fact that sometimes they present stable beliefs about gambling (e.g. possibilities of wins, strategies and control over a game), while at the same time they can present automatic thoughts that occur in so called "hot" (gambling) situations, and influence players behaviour at that particular moment. In latter case they do not necessarily represent players' thoughts in "cold" situations (when he/she is not gambling). Therefore, there is still no unanimous methodology of how to accurately identify and measure gambling-related distortions and/or how to operationalize them in surveys.

The psychotherapy approach has proven to be the most effective approach in treating pathological gamblers (Pallesen et al. 2005). While there is no clearly defined or generally accepted approach to treating pathological gamblers (Marceaux \& Melville 2011), therapeutic approaches that alter inaccurate gambler cognition, including the illusion of control, superstitions, beliefs in special skills and luck, can reduce problematic gambling behaviour, thereby confirming the importance of cognitive biases (Walker 2005, Fortune \& Goodie 2012).

In Croatia, mental health care institutions lack sufficient services that focus exclusively on the treatment of gambling addicts. In recent years specialized treatment if available in some psychiatric hospitals and through a gambling addicts' club (called KLOK). According to Torre \& Zoričić (2013), the gambling addicts' club is in fact a multi-family community and support group for gambling addicts and their families, structured on the basis of a therapeutic community. These groups are open to the entry of new members, and the exit of old members, and function on a multimodal psychotherapy approach that integrates the elements of cognitive-behavioural therapy, family systemic therapy, group analytical psychotherapy, and psycho-pharmacotherapy.

During sessions, discussions are held on everyday functioning, relationships and quality of life, but cognitive distortions concerning gambling are also corrected. The patient is guided towards recognising their own feelings and potential triggers for a relapse into gambling, methods on how to control those urges are learned, and gamblers are educated on the various aspects of the gambling disorders (Torre \& Zoričić 2013).

Considering all aforementioned studies, the aim of this paper was to explore gambling related cognitive distortions and perceived knowledge/skills versus luck in gambling activities among patients within the gambling addicts' club (KLOK). A specific aim was to explore and test differences in cognitive distortions with regards to the length of treatment and patient's age.

\section{SUBJECTS AND METHODS}

\section{Study sample}

A total of $\mathrm{N}=64$ participants treated within the gambling addicts' club (KLOK) in the City of Zagreb were included in this study. Participants were predominantly male $(\mathrm{M}=98.4 \% ; \mathrm{F}=1.6 \%)$. The age range of participants ranged from 18 to 73 years, with a mean age of Mage $=35.72$ years $\left(\mathrm{SD}_{\text {age }}=10.59\right)$. Most participants were married $(57.8 \%$ ), while $23.4 \%$ were single, $17.2 \%$ were in a relationship but not living with their partner, and one participant was divorced. About half of all participants $(48.4 \%)$ were parents. With regard to education levels, most participants had completed high-school $(71.9 \%), 20.3 \%$ have a university degree, and $6.3 \%$ have a master or a doctoral degree. One subject had completed only primary school. Most participants $(65.6 \%)$ were employed full time, while $10.9 \%$ worked occasionally or seasonally. The remaining $17.2 \%$ of participants were not employed, though $3.1 \%$ worked on student jobs, and 3.1\% were retired.

Even though we aimed at a convenience sample, it should be stated that all patients treated within the KLOK gambling addicts' club in the City of Zagreb were included in the study, so we can conclude on the bases of population of all patients in the club in December 2015.

\section{Instruments}

\section{Gambling Beliefs Scale}

The original version of the Gambling Beliefs Scale (Ricijaš et al. 2011, Dodig 2013) consists of 18 items classified into two factors: (1) superstition and incorrect understanding of probability, and (2) illusion of control. This scale has been constructed and used in previous research for the general youth population to assess their gambling related cognitive distortions. The participants responded by answering each item on a five-point agreement scale (I completely disagree - I mostly disagree - I neither agree nor disagree - I mostly agree - I completely agree).

After applying this scale to this clinical sample, based on the scree-plot and initial eigenvalues greater than 1, a two-factor solution was identified, and all the necessary parameters were met (KMO measure of sampling adequacy $=0.774$; Bartlett's Test of Sphericity $\left.\chi^{2}=369.098 ; \mathrm{dr}=78 ; \mathrm{p}<0.000\right)$. When analysing saturations of each item in a two-factor solution, five items were deleted, and the modified version of the scale consisted of 13 items categorized into twofactors with high Cronbach-alpha's reliabilities, which explain a total of $54 \%$ of the variance: $\mathrm{F} 1=$ Illusion of control $(\alpha=0.857)$ and $\mathrm{F} 2=$ Superstition and incorrect understanding of probability ( $\alpha=0.787)$. The factorial structure of the modified scale is presented in Table 1. 
Table 1. Factorial structure of the Gambling Beliefs Scale - modified version

\begin{tabular}{lc}
\hline 16. To win money with gambling, it is important to have a good system of playing. & F1 \\
4. If someone has success in gambling, it proves that he possesses the knowledge & 0.884 \\
and skills needed for gambling. & 0.835 \\
11. Skills determine how successful a gambler will be. & 0.799 \\
17. Winning in gambling is not only determined by luck. & 0.752 \\
9. Chances of winning a large sum of money with gambling are pretty high. & 0.662 \\
18. Even if a person has a series of losses, he will gain the money back if he plays long enough. & 0.591 \\
3. In the long run, with gambling one can gain more than lose. & 0.507 \\
13. There is a higher chance of winning if one uses his lucky numbers. & 0.878 \\
8. Lucky charms (e.g. clothing, talismans, lucky charms etc.) increase probability of a gambling win. \\
7. One can sense when he will have luck in gambling. \\
12. If one is losing in gambling for some time, the chances he will start to win are higher. \\
2. Some activities (e.g. rituals) increase the chances of a gambling win. \\
6. If one has a series of wins, it is probable that the wins will continue. \\
\hline
\end{tabular}

\section{Questionnaire of perceived/necessary knowledge/skills required for success in the games of chance}

In order to test gamblers' perception on the necessary knowledge/skills required to succeed in individual games of changes, a special questionnaire was constructed for the purposes of this study. The questionnaire contained a list of eight games (see Table 2.), and the task of participants was to answer on a five-point scale what they believed was necessary to succeed (to win) in these games. Examples of games were sports betting, slot machines, lotto and roulette. The five-point scale of answers was based on the continuum: $1=$ outcome depends exclusively on knowledge/skills, $3=$ outcome is equally dependent on knowledge/skills and luck; $5=$ outcome depends exclusively on luck.

\section{Data processing methods}

For descriptive purposes, response frequencies were used, while MANOVA $(2 * 2=$ length of treatment $*$ age of participants), was performed to explore and test possible differences between subgroups. SPSS-21 for Windows was used to perform statistical data analysis.

\section{Assessment procedure and ethics}

All participants in this study were asked to fill out the questionnaire during their routine group treatment sessions in the club. The questionnaire was anonymous, and participants were encouraged to answer honestly. They were informed that they could quit filling out the questionnaires at any time, without having to explain themselves or suffer any consequences. The study was approved by the Association of Clubs of Treated Gamblers and by the Ethics Committee of the School of Dental Medicine of the University of Zagreb, and it was carried out in accordance with the Helsinki Declaration.

\section{RESULTS}

Descriptive analysis of gambling beliefs in general shows tendency towards lower values of response, i.e. disagreement with statements, indicating a lower level of cognitive distortions (Table 3). Nevertheless, the distribution of results was not the same for all items, and the first four items of the first factor (F1-Illusion of control) show somewhat different distribution. For example, $27.0 \%$ of participants agreed or strongly agreed with the statement that gambling wins are not only determined by luck, meaning that elements of knowledge and skill are also important for the outcome. Higher frequencies of agreement were also present for other items of the first factor, where $15.8 \%$ agreed that a good system of playing is important for winning and $8 \%$ agreed that skills determine success. The cognitive bias of the importance of knowledge/ skills versus luck for the gambling outcome is always an interesting and important treatment issue. Therefore, we also explored their perception of its importance, specifically for different games of chance. With regards to items related to the second factor (F2Superstition and incorrect understanding of probability), much lower response frequencies were noted, with the interesting result of about $8 \%$ of patients who believe that one can sense when they will have luck in gambling, indicating the importance of intuition in gambling outcomes.

In order to explore the effects of length of treatment in the club, participants were categorized into two groups: (1) Participants in treatment for less than one year $(\mathrm{n}=32 ; 50 \%)$, and (2) Participants in treatment for longer than one year $(n=32 ; 50 \%)$. Based on chronological age, participants were also categorized into two groups: (1) Younger participants $<34$ years of age $(n=30 ; 46.9 \%)$ and (2) Older participants $>35$ years of age $(n=34 ; 53.1 \%)$. 
Table 2. Importance of knowledge/skills versus luck for successful outcomes in games of chance (\%)

\begin{tabular}{lccccc}
\hline & $\begin{array}{c}\text { Outcome is determined } \\
\text { exclusively by knowledge/skills }\end{array}$ & $\begin{array}{c}\text { Outcome is equally determined } \\
\text { by knowledge/skills and luck }\end{array}$ & $\begin{array}{c}\text { Outcome is determined } \\
\text { exclusively by luck }\end{array}$ \\
\hline Sports betting & 4.7 & 1.6 & 53.1 & 9.4 & 31.3 \\
Slot machines & 0.0 & 1.6 & 3.1 & 1.6 & 93.8 \\
Lotto & 0.0 & 0.0 & 3.1 & 0.0 & 96.9 \\
Scratch cards & 0.0 & 0.0 & 1.6 & 1.6 & 96.9 \\
Roulette & 0.0 & 1.6 & 17.2 & 7.8 & 73.4 \\
Dice games & 1.6 & 1.6 & 6.3 & 1.6 & 88.9 \\
Cards - Poker & 15.6 & 12.5 & 32.8 & 9.4 & 29.7 \\
Cards - Blackjack & 7.9 & 3.2 & 39.7 & 4.8 & 44.4 \\
\hline
\end{tabular}

Table 3. Frequencies of all items of the Gambling Beliefs Scale $(\mathrm{N}=64)$

\begin{tabular}{|c|c|c|c|c|c|}
\hline & 1 & 2 & 3 & 4 & 5 \\
\hline $\begin{array}{l}\text { 16. To win money with gambling, it is important to have } \\
\text { a good system of playing. }\end{array}$ & 52.4 & 20.6 & 11.1 & 9.5 & 6.3 \\
\hline $\begin{array}{l}\text { 4. If someone has success in gambling, it is proof that he possesses } \\
\text { knowledge and skills needed for gambling. }\end{array}$ & 54.0 & 27.0 & 14.3 & 4.8 & 0.0 \\
\hline 11. Skills determine how successful a gambler will be. & 63.5 & 20.6 & 7.9 & 4.8 & 3.2 \\
\hline 17. Winning in gambling is not only determined by luck. & 46.0 & 12.7 & 14.3 & 15.9 & 11.1 \\
\hline 9. Chances of winning a large sum of money with gambling are pretty high. & 69.8 & 15.9 & 11.1 & 3.2 & 0.0 \\
\hline $\begin{array}{l}\text { 18. Even if a person has a series of losses, he will gain the money back } \\
\text { if he plays long enough. }\end{array}$ & 87.3 & 6.3 & 6.3 & 0.0 & 0.0 \\
\hline 3. In the long run, with gambling one can gain more than lose. & 87.3 & 1.6 & 1.6 & 0.0 & 9.5 \\
\hline 13. There is a higher chance of winning if one uses his lucky numbers. & 79.4 & 11.1 & 7.9 & 1.6 & 0.0 \\
\hline $\begin{array}{l}\text { 8. Lucky charms (e.g. clothing, talismans, lucky charms, etc.) increase the } \\
\text { probability of a gambling win. }\end{array}$ & 92.1 & 4.8 & 1.6 & 1.6 & 0.0 \\
\hline 7. One can sense when he will have luck in gambling. & 68.3 & 14.3 & 9.5 & 7.9 & 0.0 \\
\hline $\begin{array}{l}\text { 12. If one is losing in gambling for some time, the chance he will start } \\
\text { to win are higher. }\end{array}$ & 76.2 & 11.1 & 6.3 & 6.3 & 0.0 \\
\hline 2. Some activities (e.g. rituals) increase chances of win in gambling. & 71.4 & 11.1 & 9.5 & 7.9 & 0.0 \\
\hline 6. If one has a series of wins, it is probable that the wins will continue. & 76.2 & 15.9 & 6.3 & 0.0 & 1.6 \\
\hline
\end{tabular}

Legend: $1=\mathrm{I}$ totally disagree, $2=\mathrm{I}$ mostly disagree, $3=\mathrm{I}$ neither agree or disagree, $4=\mathrm{I}$ mostly agree, $5=\mathrm{I}$ totally agree

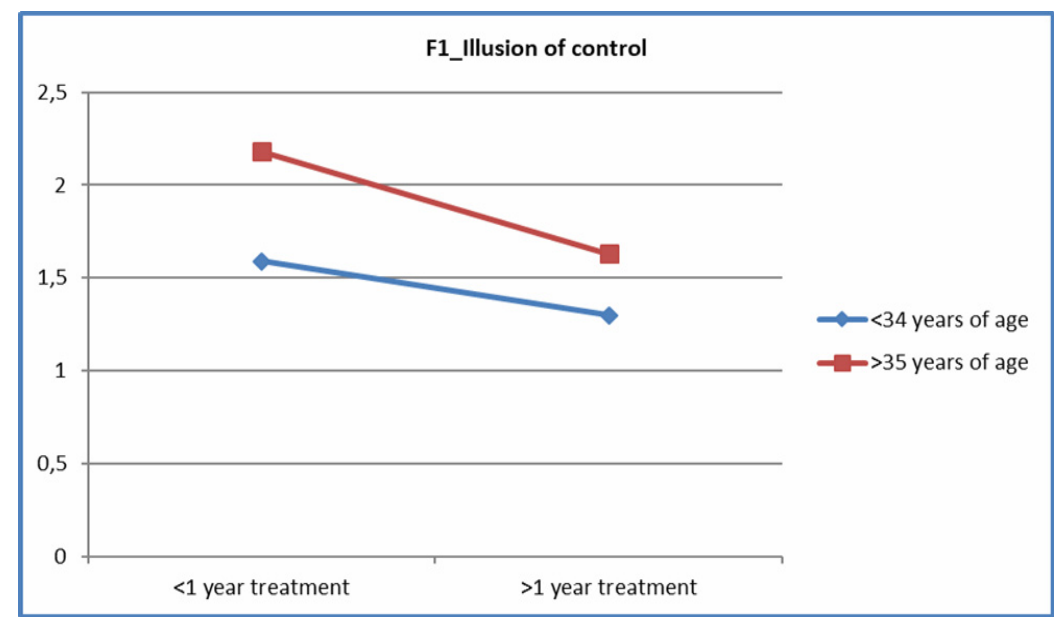

Figure 1. Differences in illusion of control with regard to length of treatment and age (MANOVA)

With the aim of exploring the effects of age and length of treatment in gambling related cognitive distortions, the general linear model (MANOVA $2 * 2$ ) was performed with 2 factors as dependent variables. The results are presented graphically in Figure 1 for Factor 1 (Illusion of control), and Figure 2 for Factor 2
(Superstition and incorrect understanding of probability). MANOVA showed two major effects to be significant: a major effect of length of treatment $(F(2,58)=5.846$; $\mathrm{p}<0.010$; par. $\left.\eta^{2}=.168\right)$, and a major effect of age $\left(F(2,58)=3.478 ; \mathrm{p}<.050\right.$; par. $\left.\eta^{2}=0.107\right)$ - with no significant interaction $(\mathrm{F}(2,58)=0.908 ; \mathrm{p}>0.050)$. 


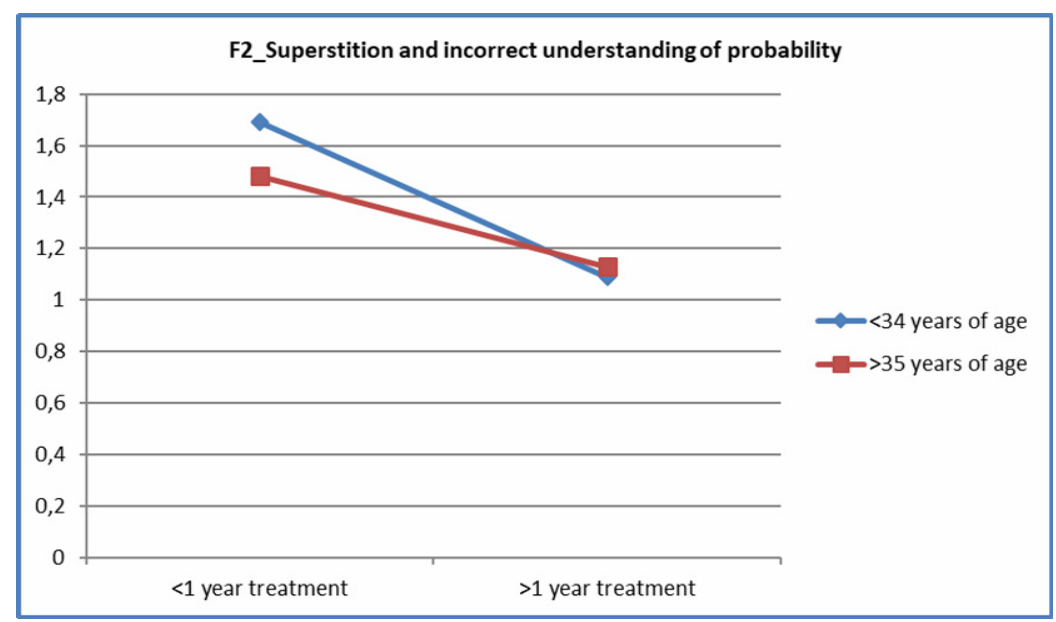

Figure 2. Differences in superstition and incorrect understanding of probability with regard to length of treatment and age (MANOVA)

The test of between subjects effects on the first factor showed that both the effects of length of treatment $(\mathrm{F}=4.087 ; \mathrm{p}<0.050)$ and patient age $(\mathrm{F}=4.936 ; \mathrm{p}<0.050)$ were significant. The significance was not strong $(p<0.050)$, but it can be concluded that patients who are in treatment longer, and younger patients, have less illusion of control over games of chance. Interaction effects were not significant $(\mathrm{F}=0.395 ; \mathrm{p}>0.050)$.

The test of between subjects effects on the second factor only showed a significant effect for the length of treatment $(\mathrm{F}=11.053 ; \mathrm{p}<0.010)$, with a moderately high value $\left(\eta^{2}=0.158\right)$. The effects of age $(\mathrm{F}=0.353$; $\mathrm{p}>0.050)$ and interaction effects $(\mathrm{F}=0.826 ; \mathrm{p}>0.050)$ were not significant. These results suggest that participants who are longer in treatment have less gambling related superstitions and less of an incorrect understanding of probability.

The illusion of control evidently plays an important role in problem gambling behaviour. The idea of having control over games of chance (gambling activities) is contradictory in itself, as chance is defined as something we have no control of. At the same time, games of chance differ in their modality of play, and therefore we explored patients' perception of the importance of knowledge/skills versus luck for successful outcomes in specific games of chance (Table 2).

Results indicate that lottery games, slot machines and dice games are not perceived as games where knowledge/skills play an important role for successful outcomes. On the contrary, over $90 \%$ of patients attributed the outcomes in these games exclusively to luck. On the other hand, the distribution was quite different for other games. Around $50 \%$ of participants perceived that knowledge/skills and luck equally determine the outcome in sports betting, while around $6 \%$ attribute outcomes in sports betting exclusively to knowledge/ skills. Around 17\% also perceived knowledge/skills and luck to be of equal importance for success in roulette. With regards to card games, around $28 \%$ of patients believe how knowledge/skills can exclusively determine their outcomes in poker, and $11 \%$ in blackjack.
MANOVA was performed to explore if patients in treatment for up to one year versus those in treatment longer, and younger versus older patients, have different perceptions on the importance of knowledge/skills and luck for the outcome in games of chance. The results are presented in Table 4 . We can see that the effects of treatment were significant in four types of games, with the mean values always in favour of participants who are in treatment longer. They had less of a perception that knowledge/skills can determine the outcomes in these games, compared to patients in the treatment less than one year (Sports betting $\mathrm{M}<1 \mathrm{y}=3.35, \mathrm{M}>1 \mathrm{y}=3.88$, par. $\eta^{2}=0.086$; Slot machines - $\mathrm{M}<1 \mathrm{y}=4.74, \mathrm{M}>1 \mathrm{y}=5.00$, par. $\eta^{2}=0.075$; Poker $\mathrm{M}<1 \mathrm{y}=2.87, \mathrm{M}>1 \mathrm{y}=3.62$, par. $\eta^{2}=0.097$; Blackjack $\mathrm{M}<1 \mathrm{y}=3.48 ; \mathrm{M}>1 \mathrm{y}=4.00$, par. $\eta^{2}=0.092$ ). Interestingly, the effects for blackjack were significant, in a way that older patients had a somewhat higher perception that knowledge/skills determine the outcome in this game, compared to younger patients $(\mathrm{M}<34=4.03, \mathrm{M}>35=3.50$, par. $\eta^{2}=0.096$ ).

\section{DISCUSSION}

This study measured cognitive distortions from two perspectives. The first one focused on gambling believes in general, while perception of necessary knowledge/skills versus luck in the gambling outcomes for each specific game presented second perspective. Justification of this approach can be seen from our results, as beliefs and perception of necessary skills can be contradictory. For example, when asked about the importance of skills for success in gambling, only $8 \%$ of participants tend to agree with it on a general level (item 11, Table 3), while the importance of skills for each game separately show different perception (Table 2). In general, participants tend to show lower levels of cognitive distortions in "cold" situations as they rationally answer specific questions. Nevertheless, cognitive distortions have been captured when assessing specific games. 
Table 4. Effects of length of treatment and participant age in perceived knowledge/skills and luck for successful outcomes in games of chance (MANOVA)

\begin{tabular}{|c|c|c|c|c|c|c|c|}
\hline & Treatment & Age & M & SD & $\begin{array}{l}\text { Treatment } \\
\mathrm{F}(8 / 52)\end{array}$ & $\begin{array}{c}\text { Age } \\
\mathrm{F}(8 / 52) \\
\end{array}$ & $\begin{array}{c}\text { Treatment x Age } \\
\qquad \mathrm{F}(8 / 52) \\
\end{array}$ \\
\hline \multirow{4}{*}{ Sports betting } & $<1$ year & $<34$ & 3.50 & 1.10 & \multirow{4}{*}{$5.52 *$} & \multirow{4}{*}{2.34} & \multirow{4}{*}{0.16} \\
\hline & l yeal & $>35$ & 3.09 & 0.94 & & & \\
\hline & $>1$ vear & $<34$ & 4.22 & 0.97 & & & \\
\hline & 1 year & $>35$ & 3.74 & 1.14 & & & \\
\hline \multirow{4}{*}{ Slot machines } & $<1$ year & $<34$ & 4.85 & 0.49 & \multirow{4}{*}{$4.78^{*}$} & \multirow{4}{*}{1.21} & \multirow{4}{*}{1.21} \\
\hline & & $>35$ & 4.55 & 1.04 & & & \\
\hline & $>1$ vear & $<34$ & 5.00 & 0.00 & & & \\
\hline & 1 year & $>35$ & 5.00 & 0.00 & & & \\
\hline \multirow{4}{*}{ Lotto } & $<1$ year & $<34$ & 4.80 & 0.62 & \multirow{4}{*}{1.11} & \multirow{4}{*}{1.11} & \multirow{4}{*}{1.11} \\
\hline & & $>35$ & 5.00 & 0.00 & & & \\
\hline & $>1$ vear & $<34$ & 5.00 & 0.00 & & & \\
\hline & I yeal & $>35$ & 5.00 & 0.00 & & & \\
\hline \multirow{4}{*}{ Scratch cards } & $<1$ year & $<34$ & 4.90 & 0.45 & \multirow{4}{*}{0.13} & \multirow{4}{*}{0.13} & \multirow{4}{*}{0.86} \\
\hline & & $>35$ & 5.00 & 0.00 & & & \\
\hline & $>1$ vear & $<34$ & 5.00 & 0.00 & & & \\
\hline & l year & $>35$ & 4.96 & 0.21 & & & \\
\hline \multirow{4}{*}{ Roulette } & $<1$ year & $<34$ & 4.50 & 0.95 & \multirow{4}{*}{0.74} & \multirow{4}{*}{0.33} & \multirow{4}{*}{0.14} \\
\hline & & $>35$ & 4.45 & 0.82 & & & \\
\hline & $>1$ vear & $<34$ & 4.78 & 0.67 & & & \\
\hline & & $>35$ & 4.57 & 0.79 & & & \\
\hline \multirow{4}{*}{ Dice games } & $<1$ year & $<34$ & 4.80 & 0.62 & \multirow{4}{*}{0.66} & \multirow{4}{*}{1.70} & \multirow{4}{*}{0.01} \\
\hline & & $>35$ & 4.55 & 0.82 & & & \\
\hline & $>1$ vear & $<34$ & 5.00 & 0.00 & & & \\
\hline & 1 yeal & $>35$ & 4.70 & 1.02 & & & \\
\hline \multirow{4}{*}{ Poker } & $<1$ year & $<34$ & 3.20 & 1.20 & \multirow{4}{*}{$6.32 *$} & \multirow{4}{*}{2.35} & \multirow{4}{*}{0.92} \\
\hline & & $>35$ & 2.27 & 1.27 & & & \\
\hline & $>1$ year & $<34$ & 3.78 & 1.48 & & & \\
\hline & 1 yedr & $>35$ & 3.57 & 1.50 & & & \\
\hline \multirow{4}{*}{ Blackjack } & $<1$ year & $<34$ & 3.80 & 0.95 & & & \\
\hline & & $>35$ & 2.91 & 1.30 & $6.01 *$ & $6.26 *$ & 0.03 \\
\hline & $>1$ year & $<34$ & 4.56 & 0.88 & & & \\
\hline & I yeal & $>35$ & 3.78 & 1.48 & & & \\
\hline
\end{tabular}

Following previous studies, this research also included age and duration of treatment as possible contributing variables. Many authors have examined the effects of different types of treatments on gamblers' cognitive processes. Ladouceur et al. (2003) showed that cognitive behavioural therapy, which is based on understanding the cognitive processes in gambling, with a focus on changing the understanding of probability and understanding the illusion of control as important objectives, was effective in correcting cognitive distortions, and thereby could be a positive influence in the treatment of pathological gamblers.

With regards to age, studies are not unanimous, and show somewhat contradictory results. For example, in a sample of 2223 adolescents, Kristiansen et al. (2014) found that older adolescents had stronger illusions of control than younger ones regarding games of chance that require both knowledge/skill and luck for success, and for those games based exclusively on luck, while age had no effect on the understanding of probability. On the contrary, the study of Tang \& Wu (2012) on three age groups (11-17, 18-25, >26 years) found that the youngest age group had the strongest cognitive distortions. Interestingly, our results revealed that older participants (over 35 years of age) showed a higher level of illusion of control than younger ones, while age showed to have no effect for superstitions and the incorrect understanding of probability. Effects of age in gamblers' cognition deserve future research as one can observe it to be a trait that gives diverse results. Age should also be considered when designing instruments to assess this construct as it presents numerous methodological challenges.

As all interventions should focus on cognitive distortions, it is reasonable to presume that length of treatment will influence the level and intensity of cognitive 
biases. Our results show that subjects in treatment longer had less cognitive distortions on both factors (F1-Illusion of control, and F2-Superstition and incorrect understanding of probability), but also that the length of treatment appears to influence the perceptions and significance of knowledge/skill and luck on gambling success assessed games. Those in treatment longer had a lower belief in the importance of knowledge/skill for the outcome of sports betting, slot machines, blackjack and poker, i.e. they had a stronger belief that a successful outcome was reliant only on luck, which is an accurate assumption and a potential protective factor for abstinence and possible relapse in the future.

Correct understanding of gambling products is an important part of decision-making process. Games of chance can be divided into two groups: (1) those based exclusively on luck, and (2) those that require a certain level of knowledge/skill in addition to luck. Therefore, we must emphasise that pure knowledge/skill will never predict an outcome in games of chance and cannot guarantee wins. Among those games based exclusively on luck, i.e. where the gambler cannot apply any knowledge/skill, are lotto, scratch cards, bingo, roulette, slot machines, and dice games, while games requiring both luck and certain knowledge/skill are usually card games (e.g. poker and blackjack). Cognitive distortions in this area are of the utmost importance for understanding persistence in gambling activities, as they contribute to gamblers' motivation to possibly improve their gambling knowledge/skills in an attempt to control the outcomes. Zhou et al. (2012) found that players who believed in luck were more inclined to play games in which luck is exclusively important for success, while those players who believe in skill leaned more towards playing games in which gambling success required both luck and a certain amount of knowledge and skill. Kristiansen et al. (2014) showed that persons with gambling problems had a pronounced belief that skills have a key role in gambling success for those games requiring a combination of luck and knowledge/skill.

With regards to sports betting and betting on horse races, results are not consistent. Some studies have indicated that knowledge and skills can have an effect, while other have shown that they do not (Rogers 1998, Ladouceur et al. 1998, Myrseth et al. 2010). Cantinotti et al. (2004) strongly argue that based on their research, skills have no influence on the outcomes in sports betting, and that this is exclusively an illusion of control. However, many gamblers tend to have a different understanding of the role of luck for the success of gambling (Wohl et al. 2007). In the present study, half of the subjects felt that knowledge/skill and luck were equally important for sports betting, while more than a third answered that only luck was important. The fact that MANOVA showed significant effects of treatment in this area is encouraging for positive treatment outcomes.
With regards to poker, Levitt \& Miles (2011) compared experienced and unexperienced players in poker tournaments, and found that experienced players outplayed the inexperienced ones, and that skill did indeed have an influence on the outcome. One-third of our participants answered that they believe how knowledge and skills are exclusively important for poker, one-third answered that both knowledge/skill and luck are equally important, while around $11 \%$ find knowledge/skills exclusively important in determining outcome for blackjack. There findings are dangerous as such perception can lead to a very strong illusion of control and future gambling behaviour. Since the results of MANOVA showed significant effects of treatment for these two card games, one can presume that interventions will in the future also positively tackle this belief. For those games based exclusively on chance, such as slot machines, lotto, scratch cards and roulette, our participants showed a tendency to believe that luck was in fact the main factor for gambling success.

There are of course some limitations in this study. First, even though the survey was conducted with the whole population of addicts treated in the capital's gambling addicts' clubs, one must mention that the sample size was rather small, and that more robust conclusions are not possible. Also, in our cross-sectional study design we do not have information about our subjects' cognitive distortions before they started the treatment nor were all subjects in their beginning of the treatment. Therefore, we can only indirectly conclude about the treatment effects. And thirdly, as noted before, measuring cognitive distortions with 'paper-pencil' instruments has its limitations, even thought Goodie \& Fortune (2013) in their metaanalysis on measuring cognitive distortions conclude that instruments with good psychometrics reveal sharply greater distortions among problem gamblers compared to non-problem gambler, and that this methodology is sufficiently robust to capture their effects.

Consequently, future studies should try to achieve a greater sample of problem gamblers (addicts) in research and measure their cognitive style longitudinally, at the very beginning of the treatment, with different time points of the treatment and in the end. Our results contribute to the better understanding of pathological gamblers' cognitive functioning, but also to tailoring psychosocial treatment in KLOK in order to achieve better therapeutic effects. Latter is especially important in the context of results that revealed the presence of distorted thought among our patients.

\section{CONCLUSIONS}

In general, our study shows moderate cognitive distortions among patients in KLOK in terms of broad beliefs, but visible non-functional attitudes towards some specific games of chance, especially sports betting and card games. With regards to age, younger and older 
patients had the same level of superstition beliefs and incorrect understanding of probability, younger participants had less pronounced illusion of control than older ones. On the other hand, all types of cognitive distortions were found to be less pronounced in participants who had been in treatment longer. With regards to specific games, the results showed a significant effect of the length of treatment in the desired directions participants in treatment longer were more inclined to perceive pure luck as a factor for any successful outcome in gambling activities.

From the above mentioned, it can be indirectly concluded that the psychosocial group treatment in KLOK can influence and reduce the level of cognitive distortions, and that it can reduce the participants' perception on the role of knowledge/skill on gambling success. These results implicate positive and supportive aspect of the treatment in gambles' addicts club and provide baseline for further research of this topic.

Finally, we believe that the tendencies described in this research are encouraging in the context of treatment effects and further medical/psychosocial interventions for gambling addicts.

\section{Acknowledgements:}

Authors would like to thank all patients in the Gambling Addicts Club for their time and effort to voluntarily participate in this study.

\section{Conflict of interest: None to declare.}

\section{Contribution of individual authors:}

Donald Stojnić contributed with the study design, data collection, data interpretation, and manuscript preparation.

Neven Ricijaš contributed with the study design, statistical analyses, data interpretation, manuscript preparation and performed multiple edits of the manuscript drafts.

Zoran Zoričić was involved with the study design and reviewed the manuscript drafts.

\section{References}

1. Cantinotti M, Ladouceur $R$ \& Jacques C: Sports betting: Can gamblers beat randomness? Psychol Addict Behav 2004; 18:143-147

2. Dodig D: Characteristics of youth gambling and determinants of adverse psychosocial consequences (Obilježja kockanja mladih $i$ odrednice štetnih psihosocijalnih posljedica). Doctoral thesis. Zagreb: Pravni fakultet 2013

3. Fortune EE \& Goodie AS: Cognitive distortions as a component and treatment focus of pathological gambling: $A$ review. Psychol Addict Behav 2012; 26:298-310

4. Goodie AS \& Fortune EE: Measuring cognitive distortions in pathological gambling: Review and metaanalyses. Psychol Addict Behav 2013; 27:730-743
5. Kristiansen S, Jensen SM \& Trabjerg MC: Youth gambling as risky business: An examination of risk perception and perception of skill and luck among Danish adolescents. JGI 2014

6. Ladouceur R: Gambling: The hidden addiction. Can J Psychiatry 2004a; 49:501-503

7. Ladouceur R: Perceptions among pathological and nonpathological gamblers. Addict Behav 2004b; 29:555-565

8. Ladouceur R, Giroux I \& Jacques C: Winning on the horses: How much strategy and knowledge are needed? J Psychol 1998; 132:133-142

9. Ladouceur R, Sylvain C, Boutin C, Lachance S, Doucet C \& Leblond J: Group therapy for pathological gamblers: a cognitive approach. Behav Res Ther 2003; 41:587-596

10. Levesque D, Sevigny S, Giroux I \& Jacques C: Psychological vulnerability and problem gambling: The mediational role of cognitive distortions. J Gambl Stud 2018; (online: https://www.ncbi.nlm.nih.gov/pubmed/29299737)

11. Levitt SD \& Miles TJ: The role of skill versus luck in poker: Evidence from the World Series of Poker. J Sports Econom 2011

12. Marceaux JC \& Melville CL: Twelve-step facilitated versus mapping-enhanced cognitive-behavioral therapy for pathological gambling: A controlled study. J Gambl Stud 2011; 27:171-190

13. Matute H, Blanco F, Yarritu I, Diaz-Lago M, Vadillo MA \& Barberia I: Illusions of causality: how they bias our everyday thinking and how they could be reduced. Front Psychol 2015; 6:888

14. Myrseth H, Brunborg GS \& Eidem M: Differences in cognitive distortions between pathological and nonpathological gamblers with preferences for chance or skill Games. J Gambl Stud 2010; 26:561-569

15. Pallesen S, Mitsem M, Kvale G, Johnsen BH \& Molde H: Outcome of psychological treatments of pathological gambling: a review and meta-analysis. Addiction 2005; 100:1412-1422

16. Ricijaš N, Dodig D, Huić A\& Kranželić V: Habits and characteristics of adolescent gambling in urban areas research report on results (Navike i obilježja kockanja adolescenata u urbanim sredinama - izvještaj o rezultatima istraživanja). Zagreb: Edukacijsko-rehabilitacijski fakultet 2011

17. Rogers P: The cognitive psychology of lottery gambling: $A$ theoretical review. J Gambl Stud 1998; 14:111-134

18. Sharpe L \& Tarrier N: Towards a cognitive-behavioural theory of problem gambling. Br J Psychiatry 1993; 162:407-12

19. Sylvain C, Ladouceur $R$ \& Boisvert JM: Cognitive and behavioral treatment of pathological gambling: a controlled study. J Consult Clin Psychol 1997; 65:727-32

20. Tang CSK \& Wu AM: Gambling-related cognitive biases and pathological gambling among youths, young adults, and mature adults in Chinese societies. J Gambl Stud 2012; 28:139-154

21. Toneatto T: Cognitive psychopathology of problem gambling. Subst Use Misuse 1999; 34:1593-1604

22. Toneatto T, Blitz-Miller T, Calderwood K, Dragonetti R \& Tsanos A: Cognitive distortions in heavy gambling. $J$ Gambl Stud 1997; 13

23. Torre $R \&$ Zoričić Z: Gambling and betting from fun to addiction (Kockanje i kladenje od zabave do ovisnosti). Zagreb: HSKLA 2013 
24. Walker MB: Problems in measuring the effectiveness of cognitive therapy for pathological gambling. J Gambl Stud 2005; 21:79-90

25. Winters $K C \&$ Kushner $M G$ : Treatment issues pertaining to pathological gamblers with a comorbid disorder. $J$ Gambl Stud 2003; 19:261

26. Wohl MJA, Young MM \& Hart KE: Self-perceptions of dispositional luck: Relationship to DSM gambling symptoms, subjective enjoyment of gambling and treatment readiness. Subst Use Misuse 2007; 42:43-63

27. Xian H, Shah KR, Phillips SM, Scherrer JF, Volberg $R$ \& Eisen SA: Association of cognitive distortions with problem and pathological gambling in adult male twins. Psychiatry Res 2008; 160:300-307

28. Zhou K, Tang H, Sun Y, Huang GH, Rao LL, Liang ZY \& Li S: Belief in luck or in skill: Which locks people into gambling? J Gambl Stud 2012; 28:379-391

Correspondence:

Donald Stojnić, MD

Department of Psychiatry, Clinical Hospital Centre "Sestre Milosrdnice"

Vinogradska cesta 29, 10000 Zagreb, Croatia

E-mail: stoj1@net.hr 